\title{
Autolesão não suicida em adolescentes: Terapia Comunitária Integrativa como estratégia de partilha e de enfrentamento*
}

\author{
Adriana Olimpia Barbosa Felipe ${ }^{1,2}$ \\ (D) https://orcid.org/0000-0002-4491-5750 \\ Zélia Marilda Rodrigues Resck ${ }^{1}$ \\ (D) https://orcid.org/0000-0002-3752-8381 \\ Vânia Regina Bressan ${ }^{1}$ \\ (D) https://orcid.org/0000-0003-2227-2755 \\ Sueli de Carvalho Vilela ${ }^{1}$ \\ (D) https://orcid.org/0000-0003-3034-3904 \\ Silvana Maria Coelho Leite Fava ${ }^{1}$ \\ (D) https://orcid.org/0000-0003-3186-9596 \\ Denis da Silva Moreira ${ }^{1}$ \\ (D) https://orcid.org/0000-0002-5055-5210
}

* Este artigo refere-se à chamada temática "Violência autoprovocada: autolesão não suicida e comportamento suicida".

${ }^{1}$ Universidade Federal de Alfenas, Escola de Enfermagem, Alfenas, MG, Brasil.

2 Bolsista da Coordenação de Aperfeiçoamento de Pessoal de Nível Superior (CAPES), Brasil.

\begin{abstract}
Objetivo: apreender por meio da Terapia Comunitária Integrativa (TCI) os fatores relacionados à autolesão não suicida em adolescentes e à contribuição da mesma para as estratégias de enfrentamento. Método: estudo qualitativo, conduzido com adolescentes que participaram das rodas de Terapia Comunitária Integrativa, as quais foram gravadas e registradas em diário de campo. Utilizou-se análise temática e fundamentou-se no Modelo de Habilidades de Vida. Resultados: a autolesão emergiu em seis rodas, como tema ou envolto a outro sofrimento vivenciado pelas adolescentes mulheres. Foram evidenciadas as categorias "Adolescência e autolesão não suicida: alívio da angustia", "Roda de Terapia Comunitária Integrativa: espaço terapêutico" e suas subcategorias. Conclusões: as adolescentes encontram na autolesão não suicida uma forma para materializar e aliviar o sofrimento decorrente de múltiplos fatores. A Terapia Comunitária revelou um espaço vivo de partilha e de ressignificação do sofrimento.
\end{abstract}

Descritores: Adolescente; Autolesão não Suicida; Estratégias de Enfrentamento; Saúde Escolar; Enfermagem.

\section{Como citar este artigo}

Felipe AOB, Resck ZMR, Bressan VR, Vilela SC, Fava SMCL, Moreira DS. Non-suicidal self-harm in adolescents: Integrative Community Therapy as a sharing and coping strategy. SMAD, Rev Eletrônica Saúde Mental Álcool Drog. 2020;16(4):75-84. doi: https://dx.doi.org/10.11606/issn.1806-6976.smad.2020.155736 


\title{
Non-suicidal self-harm in adolescents: Integrative Community Therapy as a sharing and coping strategy
}

\begin{abstract}
Objective: to learn though the Integrative Community Therapy (ICT) the factors related to non-suicidal self-harm in adolescents and their contribution to coping strategies. Method: a qualitative study, conducted with adolescents who participated in the Integrative Community Therapy wheels, which were saved and recorded in a field diary. Thematic analysis was used and it was based on the Life Skills Model. Results: self-harm has emerged on six wheels, as a theme or wrapped in other suffering. The following categories emerged from the analysis: "Adolescence and non-suicidal self-harm: Anguish relief" and "Integrative Community Therapy Wheel: Therapeutic space" and its subcategories. Conclusions: adolescents find in non-suicidal selfharm a way to materialize and alleviate the suffering resulting from multiple factors. Community Therapy revealed a living space of sharing and re-signification of suffering.
\end{abstract}

Descriptors: Adolescent; Non-Suicidal Self-Injury; Coping Strategies; School Health; Nursing.

\section{Autolesiones no suicidas en adolescentes: terapia comunitaria integradora como estrategia para compartir y afrontar}

Objetivo: aprender a través de la Terapia Comunitaria Integradora (TCI) los fatores relacionados con la autolesión no suicida en adolescentes y su contribución a las estrategias de afrontamiento. Metodo: estudio cualitativo, conducido con adolescentes que participaron en las ruedas de TCI, las cuales fueron grabadas y registradas en diario de campo. Se utilizó análisis temáticos y se fundó en el Modelo de Habilidades de Vida. Resultados: La autolesión surgió en seis ruedas, como tema vinculado a otro sufrimiento. Del análisis surgieron las categorías "Adolescencia y autolesiones no suicidas: alivio de la angustia" y "Rueda de Terapia Comunitaria Integrativa: espacio terapéutico" y sus subcategorías. Conclusiones: Las adolescentes utilizan la autolesión no suicida como forma de materializar y aliviar el sufrimiento resultante de múltiples factores. La Terapia Comunitaria reveló un espacio vivo de compartir y redefinir el sufrimiento.

Descriptores: Adolescente; Autolesión no Suicida; Estrategias de Enfrentamiento; Salud Escolar; Enfermería. 


\section{Introdução}

A adolescência é uma fase saudável, contudo, é permeada por comportamentos de vulnerabilidade que podem comprometer a saúde física e psíquica ${ }^{(1)}$. Esses comportamentos, associados à dificuldade em tomar decisões e resolver problemas, à impulsividade e à presença de estresse neste período, são fatores associados a autolesão não suicida(2).

Os termos autolesão, automutilação, autoflagelação, escarificação, escoriação ou marcas corporais são utilizados para designar pessoas que se machucam, embora não exista uma padronização do termo no contexto brasileiro(3). A autolesão é considerada como violência autoinfligida intencionalmente, ou seja, uso intencional da força física ou ameaça contra si(4). Autolesão não suicida é um fenômeno comum entre os adolescentes, com maior incidência na puberdade entre 12 a 14 anos de idade, e pode se estender(5), frequentemente evidenciado nas clínicas de psicologia e nas próprias escolas(3).

Constitui um problema global e de elevada prevalência(6), embora acredita-se que os dados são subestimados, pelo fato de os adolescentes não verbalizarem aos pais, amigos ou profissionais de saúde ${ }^{(3,7)}$. A autolesão não suicida se configura como estratégia de enfrentamento disfuncional do adolescente para o equilíbrio emocional, tendo como principais fatores de risco a violência entre os pares, as doenças mentais, o consumo de substâncias psicoativas e a negligência infantil(8), o que pode sinalizar um comprometimento psíquico(6,8). Acrescenta-se que em pesquisa conduzida com adolescentes que praticavam a autolesão não suicida e que estavam hospitalizados, 55\% apresentavam problemas emocionais e de condutas, $23,5 \%$ desordem de comportamento depressivo, $10 \%$ um episódio depressivo e 9,9\% outras alterações na saúde mental, sendo que a depressão foi um dos fatores adjuvantes para a autolesão(9).

Esses dados nos provocam inquietações que conduzem aos seguintes questionamentos: O que leva os adolescentes a praticarem a autolesão não-suicida? Eles conseguem partilhar seu sofrimento? O adolescente visualiza a TCI como estratégia de enfrentamento?

Nesse contexto, evidencia-se a corresponsabilidade dos profissionais de saúde, principalmente do enfermeiro, na implementação de estratégias que possam minimizar o sofrimento psíquico na adolescência. A Terapia Comunitária Integrativa (TCI) tem sido utilizada como uma das estratégias, a qual por meio de encontros interpessoais tem contribuído para a restauração da autoestima, autoconfiança e ampliação da percepção dos problemas, o que pode favorecer a resolução e o enfrentamento(10).

Para dar respostas às inquietações desenvolveu-se o presente estudo com o objetivo de apreender por meio da Terapia Comunitária Integrativa (TCI) os fatores relacionados à autolesão não suicida em adolescentes e a contribuição da mesma para as estratégias de enfrentamento.

A relevância social e científica do estudo está em oferecer subsídios para a elaboração de políticas públicas e atuação efetiva dos profissionais de saúde e de educação com o intuito de ampliar o conhecimento da assistência ao adolescente para as questões que transcendem o modelo biomédico, e assim articular a interdisciplinaridade da saúde e da educação na proposição de estratégias de práticas emancipatórias na promoção à saúde do adolescente.

\section{Metodologia}

Utilizou-se o Reporting Pesquisa Qualitativa COREQ $^{(11)}$ para o direcionamento do estudo. Trata-se de um estudo descritivo, exploratório, com abordagem qualitativa.

Foi desenvolvido em uma escola estadual do município do sul de Minas Gerais, que possui 600 adolescentes entre 12 a 17 anos. Para sensibilização dos responsáveis e adolescentes foi realizada uma reunião, com a presença de apenas 50 , bem como visitas em sala de aula, em que foram esclarecidos sobre os objetivos da pesquisa e a condução das rodas de TCI. Foram entregues a 450 adolescentes, os Termos de Consentimento Livre e Esclarecido e o de Assentimento, com retorno de 285, de ambos os Termos assinados.

No entanto, em decorrência da evasão escolar, mudança para outra escola, desistência em continuar nas rodas, apenas 150 adolescentes matriculados no Ensino Fundamental e Médio participaram de forma contínua das 60 rodas. Para o presente estudo, foram consideradas apenas seis rodas que referenciaram a temática, autolesão não suicida, perfazendo 66 adolescentes.

Utilizou-se as rodas de TCIs para a coleta de dados, espaço para a partilha entre os adolescentes de suas inquietações, sofrimentos e conquistas. A TCI se configura no desenvolvimento de seis passos, a saber: acolhimento; celebração; escolha da temática; a contextualização do tema; a problematização e o encerramento(10).

Foram conduzidas na escola, no período de fevereiro a agosto de 2017, durante o período de aulas. Elegeu-se seis rodas de TCIs com seis grupos de adolescentes de ambos os sexos, havendo em média 11 participantes, em cada grupo. Somente participaram das rodas de TCI os adolescentes, os facilitadores e a pesquisadora, não havendo nenhum outro participante.

Os facilitadores que conduziram as rodas de TCI foram enfermeiros, psicólogos e assistente social com formação e vivencia especifica em TCI, sendo cinco 
mulheres e dois homens, com titulação de doutor (3), mestre (1) e especialista (3).

Quanto ao relacionamento e o conhecimento dos participantes em relação aos facilitadores e a pesquisadora, as rodas de TCI foram conduzidas de forma dinâmica e houve aproximação entre todos.

Os dados foram coletados pela pesquisadora, como observadora, por meio de gravador digital e anotações no diário de campo, durante a condução das rodas, que teve duração 60 a $80 \mathrm{~min}$.

Os dados relacionados ao objeto do estudo surgiram em cinco rodas, face à repetição das informações, optou-se por registrar mais uma roda com a temática, consolidando a saturação dos dados. As transcrições dos depoimentos não foram devolvidas aos participantes, uma vez que o feedback ocorre no encerramento de cada roda de TCI.

Para a organização dos dados, adotou-se a Análise de Conteúdo Temática ${ }^{12}$, envolvendo as fases préanálise, exploração, tratamento do material, inferência e interpretação, realizada por três pesquisadores. Apreendeu-se dos depoimentos e das anotações no diário de campo, duas categorias, sendo uma com duas e a outra, com três subcategorias. A análise foi fundamentada no Modelo de Habilidades de Vida, que engloba autoconhecimento, empatia, comunicação eficaz, relacionamentos interpessoais, tomada de decisão, resolução de problemas, pensamento crítico e criativo, saber lidar com os sentimentos e as emoções e a lidar com o estresse ${ }^{(13)}$. Para preservar o anonimato, utilizou-se a nomeação dos participantes pelo nome de flores.

O estudo foi aprovado pelo Comitê de Ética em Pesquisa da Universidade Federal de Alfenas, Unifal-MG, sob o Parecer 1.725.520, CAAE 58831216.8.0000.5142.

\section{Resultados}

A autolesão não suicida foi mencionada apenas nos depoimentos das mulheres adolescentes, como tema principal ou envolto a outro sofrimento vivenciado por elas, emergindo duas categorias e suas subcategorias, conforme apresentadas na Figura 1.

$\mathrm{Na}$ primeira categoria a Adolescência e autolesão não suicida: alívio da angústia expressa os sentimentos negativos vivenciados pelas adolescentes nos momentos de crise. Emergiu-se a subcategoria: "autolesão não suicida: conflitos vivenciados", em que se apreende sentimentos de angústia, raiva, impulsividade, tristeza e estresse experenciados pelas adolescentes como fatores desencadeadores desse processo: sinto aliviada quando me corto, desconto no meu corpo [...] eu não tenho paciência (Angélica); unho o meu corpo quando estou com raiva. A raiva controla a gente. Perco a paciência e me corto (Margarida); corto o pulso, com raiva e estresso por qualquer coisa (Violeta); Também me corto, quando estou muito estressada [...] me corto em vários lugares (Bromélia); [...] depende quando estou muito triste me corto com a lâmina de apontador. Quando estou triste, com raiva, corto o pulso [...] (mostra corte no pulso) e na perna $[\ldots]$ (Rosa).

A morte de um dos pais, a violência, a falta de diálogo, os conflitos familiares e sociais, e as questões relacionadas ao próprio desenvolvimento pessoal também foram relatadas como disparadores para a autolesão não suicida: [...] começou há 3 anos, quando vim morar [...] com minha mãe, depois que meu pai morreu. Nós não damos certo, brigamos por qualquer coisa. Não tenho como bater na minha mãe, agrido a mim mesma (Angélica); [...] a primeira vez, foi por causa do meu pai que morreu, passei a faca na minha perna [...] teve que dar ponto, falei que tinha sido o cachorro que mordeu [...] tinha 9 anos. Me sinto sozinha [...] minha mãe fica apenas no quarto dela. Não desabafo [...] a gente sofre (mostra o braço com o corte) (Rosa); [...] me corto todos os dias, por causa das brigas lá em casa (Íris); [...] sabe tentei me matar [...] me cortei [...] por causa das brigas dos familiares (Violeta); Também me corto, minha irmã é muito esquisita, mexe com coisas ruim (droga). Já me cortei em vários lugares. Faço isso, porque não posso bater na minha irmã, pois está gravida (Bromélia).

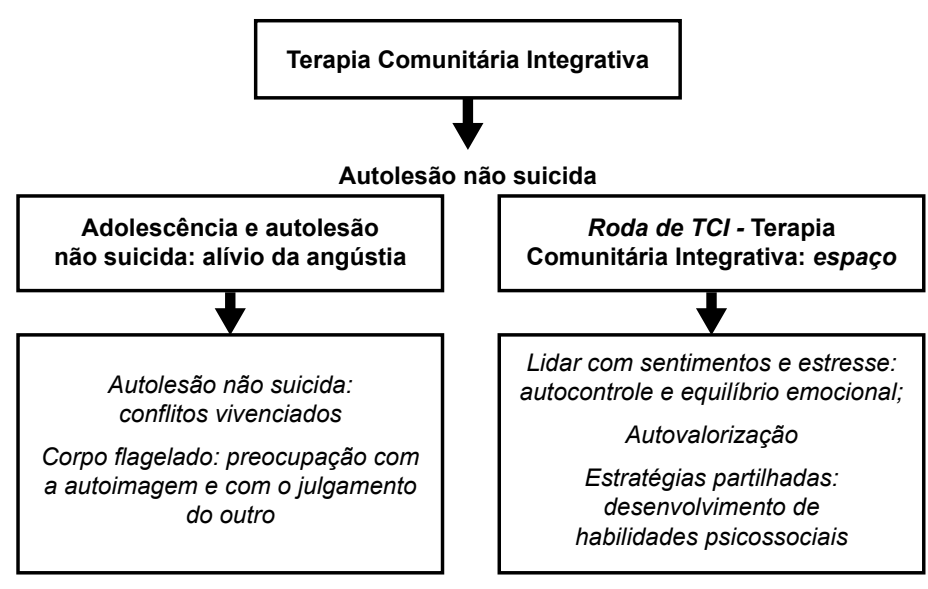

Figura 1- Diagrama das Categorias e subcategorias identificadas nas rodas de TCI 
A violência entre os pares foi sinalizada como uma problemática com repercussões emocionais negativas entre as adolescentes que podem contribuir para a autolesão não suicida [...] a pessoa que sofre bullying ela pode se cortar, até se matar. Então não é brincadeira, pode acabar com a vida do outro. Não aguento o ódio de me ver no espelho, sofrer o bullying na escola [...] quebrei o espelho e me cortei. Tem coisas que a pessoa fala que me magoa, para mim não tem mais sentido o mundo (Jasmin); [...] as crianças me chamavam de bastarda e me maltratava [...] as crianças da escola ficavam me chateando. Me cortei duas vezes por causa disso. Os colegas desta escola também fazem a mesma coisa, eu perdi a paciência e me cortei (Margarida).

A homofobia familiar e da sociedade provoca dor e sofrimento que permeiam a vida das adolescentes homossexuais que vê na autolesão o alívio e a calmaria, como afirma Dália. [...] o preconceito está em casa, na rua e na escola. Sinto raiva, por que me sinto agredida. Isso me deixa triste $[. .$.$] o que fazem comigo, não quero que façam com$ o outro. O pai não gosta de mim, porque sou lésbica, a relação é difícil. Vivo isso na escola e na sociedade [...] sinto raiva e impulsividade [...] roo unha e me corto [...] o pai é o que mais me incomoda (Dália).

A autolesão não suicida para essas adolescentes é apontada como uma das maneiras encontradas para aliviar os sentimentos negativos e expressar suas emoções: [...] sinto alívio, calma e desconto em mim (Dália); [...] sinto aliviada com o estresse. É depois de cortar e como se não tivesse nada (Violeta); [...] não sinto dor com o corte [...] alívio (Camélia); [...] me cortar é uma delícia, é mais fácil sentir dor no corte do que a dor interna (Hortênsia); [...] escutar música, dançar e fazer sexo não alivia tanto quanto me cortar (Angélica).

Ressalta-se que enquanto para as mulheres o corpo marcado pela autolesão não suicida significa o alívio do sofrimento, porque conseguem externalizar aquilo que Ihe ferem, para os homens, produz maior dor e aumenta ainda mais o sofrimento. Um dos adolescentes faz uma analogia comparando os efeitos negativos da mesma com o uso de drogas, como descrito no depoimento [...] não adianta se cortar [...] acredito que se automutilar doe para caramba. É igual a usar droga, usa a droga e depois o problema está lá (Lírio).

Quanto à subcategoria corpo flagelado: a preocupação com a autoimagem e com o julgamento do outro pode ser observado nos relatos das vivências das adolescentes: [...] tem gente que acha bobagem, agente se cortar, mas só quem passa [...] não devemos julgar (Dália); $[\ldots]$ as pessoas só quer julgar (Bromélia); [...] corto [...] com lâmina de apontador e faca. Minha mãe não sabe (Íris); [...] com a agulha perfuro e deixo o sangue sair [...] minha mãe não sabe, já cortei várias vezes (Camélia).

Observou-se que embora a autolesão não suicida seja uma forma de exteriorizar o sofrimento, o corpo marcado não é exteriorizado, e para tanto as adolescentes fazem uso de vestimentas que encobrem essas marcas: [...] uso blusa de frio, calça comprida sempre, mesmo no calor, para que ninguém veja e critica. Gostaria de parar [...] vai ficar marca no meu corpo (puxa a blusa e mostra o corpo ferido) (Angélica). Percebe-se a dualidade de sentimentos relacionadas as marcas indeléveis do sofrimento no corpo, ora vista como algo prazeroso, por algumas adolescentes, ora como marcas de arrependimento e revolta de si como referenciada na descrição de Margarida [...] depois, sinto a culpa de tudo, ódio e tristeza de mim mesmo.

$\mathrm{Na}$ segunda categoria, Roda de TCI: espaço terapêutico, apreende-se que as TCI representaram oportunidades de escuta, de dialogicidade e de partilha, o que permitiu ao mesmo tempo aos adolescentes externalizar o sofrimento e ampliar o olhar sobre a situação vivida. A subcategoria lidar com sentimentos e estresse: autocontrole e equilíbrio emocional; sinaliza que algumas adolescentes apresentam tentativas de controle da raiva e da impulsividade utilizando-se de algumas estratégias compartilhadas na roda: [...] fui na psicóloga e ela pediu para respirar. [...] controlar me acalma (Margarida) [...] preciso me controlar. Eu respiro, penso bem, deito e às vezes melhora (Violeta); [...] fazer coisas boas como: ouvir música, dançar, caminhar para tentar minimizar o estresse e não se automutilar [...] Tentar controlar o impulso (Margarida, Violeta, Andressa); [...] dar um abraço em uma criança, ficar com uma criança também ajuda (Bromélia).

A autovalorização é a segunda subcategoria que foi revelada nas falas das adolescentes que participaram das rodas de TCI como relevante para enfrentar os conflitos vividos: [...] aprendi que não devo sofrer, devo me aceitar do jeito que sou (Dália); [...] é importante nos valorizar, olhar para o espelho [...] não acreditar no que o outro fala, eles não me conhecem (Tulipa); [...] eu tenho que acreditar em mim, para me superar (Jasmim).

Desse modo, o espaço terapêutico da TCI permitiu às adolescentes externalizarem seus sentimentos, e identificar a importância de algumas habilidades psicossociais para o enfrentamento do sofrimento psíquico/emocional, como a comunicação, para o diálogo e escuta, o relacionamento interpessoal e a empatia [...] é importante nós desabafar [...] conversar com os amigos (Angélica, Margarida, Violeta); [...] eu nunca falei sobre isso (bullying, preconceito na escola e o me cortar), sofri calada mais de quatro anos (Muito choro). Foi muito bom falar na roda, pois assim as pessoas aprendem que é importante pensar antes de fazer [...] colocar no lugar do outro (Jasmim); [...] nós não estamos sozinha neste mundo (Angélica, Margarida, Tulipa); [...] já fiz bullying (apelidar e xingar) com uma pessoa que está aqui na roda, e também influenciava os amigos a fazer [...] peço desculpa ou melhor perdão fulana, eu não conversava com ela [...] (choro) (Palma). 
Percebe-se que as adolescentes enfatizam a importância de se criar na escola espaços terapêuticos, como as rodas de TCI, para favorecer a sensibilização para o exercício da empatia: [...] a escola tem que fazer mais coisas, vou colocar isso para a direção da escola (Jasmim); [...] a adolescência é problemática, precisa de apoio (Tulipa); [...] sabe, depois que comecei a fazer as rodas na escola aprendi várias coisas boas, como saber respeitar o outro, não fazer com outro o que não quero que faça comigo. Senti muito mais tranquilidade após as rodas (Orquídea).

\section{Discussão}

No que tange à categoria Adolescência e autolesão não suicida: alívio da angústia, pode-se inferir que está associada a desregulação emocional, uma vez que as adolescentes têm dificuldade em regular os comportamentos impulsivos diante do sofrimento ${ }^{(14)}$. Assim, a autolesão é vivenciada como uma forma de aliviar o sofrimento mental, também evidenciado em estudo com adolescentes da Irlanda do Norte ${ }^{(15)}$. O fato de autolesar decorre do conflito que o adolescente está experenciando, e que pode produzir o alívio da tensão, a tentativa de fuga e a sinalização de mal-estar(16), o que remete para a subcategoria autolesão não suicida: conflitos vivenciados, do presente estudo, uma vez as adolescentes revelaram a raiva, a impulsividade, o estresse e a tristeza. Neste sentido, evidencia-se que essas adolescentes ainda precisam se apropriar das habilidades de vida para lidar com os sentimentos, as emoções e o estresse na resolução dos conflitos, minimizando o mal-estar psicoemocional.

Neste contexto, ressalta-se que o estresse, a ansiedade e a depressão atuam como gatilho para ativar o mecanismo disfuncional de regulação das emoções, o que pode contribuir para autolesão não suicida(2). Investigação conduzida com três grupos de adolescentes e suas mães, o primeiro com histórico de autolesão corporal, o segundo com depressão e o terceiro grupo controle, detectou-se no primeiro maiores taxas de ansiedade, depressão, comportamentos delinquentes, transtornos de condutas, sintomas maníacos, desesperança, ideação suicida, desregulação emocional, impulsividade e o consumo de substâncias psicoativas ${ }^{(14)}$.

Ainda quanto à gênese da autolesão não suicida, além dos problemas individuais encontram-se também os problemas familiares e sociais( ${ }^{(6)}$. O que se aproxima muito da realidade vivenciada pelas adolescentes do presente estudo ao referenciar que a violência e os conflitos familiares são geradores de ansiedade, da raiva e que culminam para a autolesão não suicida, como um mecanismo de apaziguar o sofrimento igualmente reforçado pela literatura(17). No contexto das habilidades de vida, as adolescentes desse estudo apresentam dificuldades nas relações interpessoais e de comunicação com a família.

Complementa-se que os conflitos familiares foram considerados como disparadores da autolesão, uma vez que os relatos expressaram sentimentos de sofrimento pela falta de afetividade da mãe e a morte do pai. A literatura aponta que a autolesão não suicida está associada a experiências dolorosas que podem ter sido vivenciadas desde a infância( ${ }^{(9)}$. O sentimento de abandono e de vazio afetivo na relação com a mãe durante a infância causa aniquilamento do eu e que silenciosamente aloja o trauma com cicatrizes e feridas que podem romper em sofrimento psíquico durante a adolescência(18). Desse modo, os cortes corporais são apenas um reflexo de todo esse processo de sofrimento com o objetivo de aliviar a dor privada para torna-la pública, contribuindo para regular o seu afeto e estabelecer limites interpessoais ${ }^{(9,19)}$. Para tanto, a autolesão não suicida é uma maneira que o adolescente tem de projetar suas tensões em seu corpo para controla-las(20), de forma que a tensão e angustia se materializam.

Constatou-se nos depoimentos de Jasmim e de Margarida que as relações interpessoais marcadas pela violência no espaço escolar e pela falta de empatia e de comunicação entre os pares, foram destacadas como gênese do sofrimento que contribuíram para a autolesão. As adolescentes internalizam o sofrimento provocado pela violência e acabam solitárias, tímidas e inseguras, o que pode resultar em anorexia, bulimia, depressão e autolesão(21). A violência, seja pela agressão física ou verbal, está diretamente associada à autolesão e ideação suicida em adolescentes, sendo que essas relações são parcialmente mediadas pelas emoções negativas. Os adolescentes expostos a alta parentalidade e com maior autocontrole de si, minimizam os danos negativos da relação entre o bullying, autolesão e ideação suicida(22).

No presente estudo, a violência familiar, social e entre os pares em relação ao estigma da homossexualidade é vivenciada com fragilidade emocional por Dália, o que Ihe dificulta tomar decisões e resolver os problemas sem provocar danos a si mesma. A violência a esse grupo é provocada pelos membros da família e da sociedade e impacta negativamente na saúde mental, aumentando a vulnerabilidade para comportamento de risco(23). Neste contexto, o sofrimento gerado pode comprometer a capacidade de tomada de decisão e de resolução de problemas.

Evidencia-se ainda que a comunicação e o relacionamento interpessoal conflituoso entre os familiares e seus pares, são questões geradoras de 
estresse e de sentimentos negativos nas adolescentes que praticam a autolesão. Os resultados do presente estudo coadunam com a literatura, uma vez que identificou que os adolescentes com condutas autolesivas, apresentavam dificuldades em resolver os problemas e em tomar decisões, e apresentaram comportamentos impulsivos e dificuldade na regulação das emoções ${ }^{(2)}$.

A autolesão não suicida é experienciada pelas adolescentes como um mecanismo de restabelecer o equilíbrio, e demarca a expressão de um conflito, ou seja, um recurso desesperado para minimizar o sofrimento psíquico ${ }^{(3,17)}$. As marcas do sofrimento, de emoções e de dor precisam ser materializadas no seu corpo, não podendo ficar apenas no registro psíquico, o que contribui para reduzir a tensão interna, uma vez que a dor psíquica é liberada na dor física(19).

Autores $^{(24)}$ inferem que esse comportamento é para regular o afeto e as emoções, tendo em vista que libera a produção de opióides endógenos, principalmente a endorfina e encefalina porque os níveis dessas substâncias são baixos neste grupo. Esse efeito é experienciado pelas adolescentes e provoca um apogeu de bem-estar incomparável com o ato de dançar, de ouvir música, assim como o orgasmo sentido durante a atividade sexual(3), o que coaduna com o depoimento de Angélica, no presente estudo.

A autolesão não suicida recorrente é um processo viciante, na tentativa da jovem manter-se viva e elaborar os traumas experimentados em sua vida(18-19), uma vez que após esse comportamento a adolescente parece recuperar o sofrimento interno. Contudo, todo esse processo é apenas uma ilusão porque as ameaças traumáticas permanecem, principalmente quando não se tem um apoio parental adequado(20). É valido ressaltar que essa situação é reconhecida por um adolescente que não praticava a automutilação, e dizia que o ato de se cortar não resolverá o seu sofrimento.

Outra subcategoria, refere ao corpo flagelado: a preocupação com a autoimagem e com o julgamento do outro, as adolescentes desvelaram nos depoimentos que a autolesão suicida é um ato oculto, uma vez que se procura a invisibilidade das marcas por meio de roupas para que não haja julgamento e exposição da sua imagem.

O comportamento autolesivo não suicida exige da adolescente a necessidade de reclusão e de se fechar para o mundo, porque é tido como perigoso e proibido(25). Além do sofrimento causador da autolesão, elas ainda experenciaram o sentimento de solidão e isolamento, uma vez que não tem com que compartilhar a dor(17). Os seres humanos dependem da proteção do outro para a sua integração imaginária, contudo o outro também pode ser fonte de ameaça e de hostilidade ${ }^{(17)}$. $\mathrm{O}$ ato de autolesar é inaceitável por muitos, o que se torna difícil a comunicação dessa situação com os pais, familiares e $\operatorname{amigos}^{(3)}$.

Acrescenta-se que na vida contemporânea parece existir uma negação em relação ao sofrimento e a dor tanto para si próprio, quanto para o outro, o que repercute na invisibilidade desse processo. Assim, a autolesão é a descarga de uma tensão ou de um sofrimento que não pode ser revelada ao outro(17).

Ainda nesta subcategoria, observa-se que as adolescentes apresentam dualidade de sentimentos, uma vez que apesar de referenciar a necessidade de repetir a autoflagelação, também manifestam o desejo de parar com esse comportamento, uma vez que o corpo está marcado, e, como consequência, se sentem culpadas, tristes e referem odiar-se. Hipotetiza-se que as adolescentes que se autolesionam estão mergulhadas em um quadro de melancolia, em que o amor, o ódio e a culpa se misturam em pensamentos de dor e de prazer $^{(25)}$. O corpo se torna um registro vivo das inquietações, do medo e da dor, e que vão deixar as marcas permanentes ${ }^{(19)}$.

Nessa lógica, a Roda de TCI: "espaço terapêutico", segunda categoria do estudo, favoreceu partilhar e sensibilizar para algumas das habilidades psicossociais como, a empatia, a comunicação eficaz, os relacionamentos interpessoais, a resolução de problemas, saber lidar com os sentimentos, como as emoções e o estresse, o que permite o reequilíbrio emocional. Desse modo, a TCI favorece a horizontalidade, em que todos são iguais, o que permite a partilha de sofrimentos, carências, necessidades e experiências de vida(26), e ao mesmo tempo sensibiliza a partilha de estratégias para o enfrentamento dos desafios $^{(27)}$. Portanto, a TCI funciona como mola propulsora para o empoderamento e resiliência, e assim contribui para a qualidade de vida, a prevenção do sofrimento e a promoção da saúde mental(27).

A autolesão não suicida poderá deixar de existir a partir do momento que a adolescente passar a existir para o outro e em presença de si mesmo(17). Nesta perspectiva, pode-se considerar a importância do autocontrole, o que justifica a nomeação da subcategoria "lidar com sentimentos e estresse: autocontrole e equilíbrio emocional". Apreende-se pelo depoimento de Margarida e Violeta que a maneira de se controlar e de saber lidar com os sentimentos e com estresse reduzem a impulsividade para a autolesão.

E para tanto, a autovalorização, segunda subcategoria, e também referenciada em estudo, constitui uma das estratégias dos adolescentes para reduzir os conflitos vivenciados, sendo esse um período 
relevante para reforçar a maturidade biopsicossocial com vista a sua emancipação(26).

A partilha propiciada pelas rodas de TCI possibilitou às adolescentes o desenvolvimento de habilidades psicossociais que veio a contribuir com a socialização e a ressignificação do sofrimento. Os adolescentes relataram que a comunicação entre os pares é um antagonista do sofrimento, contribui na prevenção da violência entre si, e que a escola deve ser um espaço efetivo para a prevenção das vulnerabilidades que geram sofrimento. Estudo apresenta que a comunicação entre os pares auxilia os adolescentes a partilhar os sentimentos, contribui no enfrentamento dos conflitos e torna-se fonte de apoio emocional(3).

Neste sentido, as atividades de recreação, as atitudes motivadoras e o fortalecimento de redes de amizades positivas na escola contribuem para a promoção do bem-estar, da resiliência e da autoestima minimizando a necessidade de praticar a autolesão(7). Uma vez que propiciam o desenvolvimento de algumas das competências psicoemocionais, como o relacionamento interpessoal, facilitando a habilidade em lidar com as emoções bem como auxiliar no autoconhecimento.

A literatura reitera a importância dos programas de prevenção e de enfrentamento da violência, desde que valorizado o contexto escolar e de vida dos adolescentes e de seus familiares, evitando excluir e marginalizar os que sofrem ${ }^{(28)}$. Almeja-se que essas ações sejam constantes na escola e que além de contribuir na prevenção dos conflitos existentes, as mesmas devem reforçar o desenvolvimento de qualidades positivas como a habilidade da regulação emocional com vista a lidar com o estresse e a comunicação, e assim contribuir para que os adolescentes se posicionem conscientemente perante as incertezas da vida(15,21).

As estratégias de intervenção dos profissionais de saúde no espaço micropolítico escolar contribuem para fortalecer a Política Nacional de Saúde Mental InfantoJuvenil, a qual determina que não existe produção de saúde sem a produção de saúde mental. Destaca-se, neste âmbito a importância de desenvolver ações com o propósito de acolher, escutar, cuidar e promover ambientes saudáveis, visando melhorar a qualidade de vida e o desenvolvimento psicoemocional e que leve em conta as singularidades de cada um(1).

Um fato que deve ser elucidado é que apesar das adolescentes atribuírem o sofrimento e os sentimentos negativos, principalmente, aos conflitos e a falta de diálogo entre os familiares, eles não conseguem ou não encontram espaço para partilhar esse sofrimento com os mesmos, a fim de minimiza-lo e nem expressar a sua relevância como estratégia durante a TCI. Reforça-se a necessidade de mudanças de comportamento entre os membros familiares para facilitar a relação interpessoal entre eles ${ }^{(29)}$.

\section{Considerações finais}

Apreendeu-se no presente estudo que a autolesão não suicida é uma realidade vivenciada por adolescentes mulheres, uma forma para materializar e aliviar o sofrimento decorrente de múltiplos fatores entre eles a raiva, o estresse, a impulsividade, a tristeza, a violência entre os pares, a falta de comunicação e relações familiares e sociais conflituosas.

As adolescentes desvelaram a TCI como oportunidade para partilhar e ressignificar o sofrimento, o que permitiu trabalhar no coletivo as habilidades psicossociais como a autovalorização, o autoconhecimento, a empatia, a comunicação efetiva entre os pares que oportunizou o diálogo e a escuta, o equilíbrio emocional e a importância dos relacionamentos interpessoais para minimizar os problemas vivenciados.

Embora retrate a realidade local, que não permite generalizações, as contribuições para a enfermagem se referem à aproximação com o contexto escolar e com os adolescentes e à apreensão das experiências de sofrimento vivenciado, como o comportamento de automutilação não suicida. E ainda, reconhecer as potencialidades da TCI, como estratégia para a ressignificação e o papel do enfermeiro como agente de transformação social.

\section{Referências}

1. Ministério da Saúde (BR). Atenção psicossocial a crianças e adolescentes no SUS: tecendo redes para garantir direitos. Brasília: Ministério da Saúde; 2014. [Acesso 15 set 2017]. Disponível em: bvsms.saude. gov.br/bvs/publicacoes/atencao_psicossocial_criancas_ adolescentes_sus.pdf

2.Arcoverde RL, Soares LSLC. Funções Neuropsicológicas Associadas a Condutas Autolesivas: Revisão Integrativa de Literatura. Psicol Reflex Crít. 2012; 25(2): 293-300. doi: http://dx.doi.org/10.1590/ S0102-79722012000200011

3.Araujo JFB, Chatelard DS, Carvalho IS, Viana TC. O corpo na dor: automutilação, masoquismo e pulsão. Estilos Clín. 2016; 21(2): 497-515. doi: http:// dx.doi.org/http//dx.doi.org/0.11606/issn.1981-1624. v21i2p497-515.

4.Krug EG, Dahlberg LL, Mercy AB, Zwi AB, Lozano R. World report on violence and health. Geneva: World Health Organization; 2002. [cited Jun 22 2020]. Available from: https://opas.org.br/wp-content/ uploads/2015/09/relatorio-mundial-violencia-saude.pdf 
5.Lenkiewicz K, Racicka E, Bryńska, A. Self-injuryplacement in mental disordes classifications, risk factors and primary mechanisms. Review of the literature. Psychiatr Pol. 2017; 51(2): 323-34. doi: https://doi. org/10.12740/PP/62655

6.Guerreiro DF, Sampaio D. Comportamentos autolesivos em adolescentes: uma revisão da literatura com foco na investigação em língua portuguesa. Rev Port Saúder Pública. 2013; 31(2): 204-13. doi: http:// dx.doi.org/10.1016/j.rpsp.2013.05.001

7.Hall B, Place M. Cutting to cope - a modern adolescent phenomenon. Child Care Health Dev. 2010; 36(5): 6239. doi: 10.1111/j.1365-2214.2010.01095.x

8. Plener PL, Kaess M, Schmahl C, Pollak S, Fegert IM, Brown R. Nonsuicidal self-injury in adolescents. Dtsch Arztebl Int. 2018; 115(3): 23-30. doi: 10.3238/ arztebl.2018.0023.

9.Radziwillowicz W, Lewandowsk M. From traumatic events and dissociation to body image and depression symptoms - in search of self-destruction syndrome in adolescents who engage in nonsuicidal self-injury. Psychiatr Pol. 2017;51(2):283-301. doi: https://doi. org/10.12740/PP/63801

10.Barreto AP. Terapia Comunitária: passo a passo. 4 ed. Fortaleza: Gráfica LCR; 2008.

11. Tong A, Sainsbury $P$, Craig J. Consolidated criterio for reporting qualitative research (COREQ): a 32item checklist for interviews and focus group. Int Qual Health Care. 2007; 19(6):349-57. doi: https://doi. org/10.1093/intqhc/mzm042

12.Bardin L. Análise de conteúdo. Lisboa: Edições 70; 2009.

13. World Health Organization (WHO). Programme on Mental Health: Division of Mental Health, Life Skills Education in Schools. Genebra;1997.

14.Crowell SE, Beauchaine TP, Hsiao RC, Vasilev CA, Yaptangco M, Linehan MM. Differentiatig adolescent self-injury from adolescent depression: possible implications for bordeline personality development. J Abnorm Child Psychol. 2012; 40(1):45-57. doi: https:// doi.org/10.1007/s10802-011-9578-3

15. Rasmussen S, Hawton K, Philpott-Morgan S, O Connor RC. Why do adolescentes self-harm? Crisis. 2016; 37(3):176-83. doi: 10.1027/0227-5910/a000369 16.Jorge JC, Queiros O, Saraiva J. Descodificação dos comportamentos autolesivos sem intenção suicida. Estudo qualitativo das funções e significados na adolescência. Aná Psicol. 2015; 33(2):207-19. doi: http://dx.doi.org/10.14417/ap.991.

17. Fortes I, Macedo MMK. Self-mutilation in adolescence - scratches in the otherness experience. Psicogente. 2017; 20 (38):353-67. doi: http://doi. org/10.17081/psico.20.38.2556
18.Damous I, Klautau P. Marcas do infantil na adolescência: automutilação como atualização de traumas precoces. Tempo Psicanal. [Internet]. 2016;48(2):95-113. [Acesso 20 maio 2017]. Available from: http://pepsic.bvsalud.org/pdf/tpsi/v48n2/ v48n1a07.pdf

19.Vilhena M, Prado YZC. Dor, angústia e automutilação em jovens - considerações psicanalíticas. Adolesc Saúde. [Internet]. 2015; 12(2):94-8. [Acesso 30 jun 2017]. Disponível em: http://www.adolescenciaesaude.com/ detalhe_artigo.asp?id $=507$

20.Drieu D, Proia-Lelouey N, Zanello F. Ataques ao corpo e traumatofilia na adolescência. Ágora. (Rio Janeiro). 2011; 14 (1):9-20. doi: http://dx.doi.org/10.1590/ S1516-14982011000100001.

21. Nascimento TLN. Bullying: a realidade dolorida de um fenômeno sem distinção de gêneros. Em Aberto. [Internet]. 2014; 27(92):89-98. doi: http://dx.doi. org/10.24109/2176-6673.emaberto.27i92.2442

22. Hay C, Meldrum R. Bullying victimization and adolescent self-harm: testing hypotheses from general strain theory. J Youth Adoesc. 2010; 39:446-59. doi: 10.1007/s10964-009-9502-0

23. Albuquerque GA, Parentez JS, Bélem JM, Garcia CL. Violência psicológica em lésbicas, gays, bissexuais, travestis e transexuais no interior do Ceará, Brasil. Saúde Debate. 2016; 40(109):100-11. doi: http:// dx.doi.org/10.1590/0103-1104201610908.

24.Bresin K, Gordon KH. Endogenous opioids and nonsuicidal self-injury: a mechanism of affect regulation. Neurosci Biobehav Rev. 2013; 37:374:83. doi: 10.1016/j.neubiorev.2013.01.020

25.Cedaro JJ, Nascimento JPG. Dor e gozo: relatos de mulheres jovens sobre automutilações. Psicol. 2013; 24(2):203-23. doi: http://dx.doi.org/10.1590/ S0103-65642013000200002.

26.Zago FC, Bredariol ACP, Mesquita DP. A aplicação da Terapia Comunitária na intervenção com adolescentes: novas estratégias de prevenção e promoção. Cad Bras Ter Ocup. 2013; 21(2):361-71. doi: http://dx.doi. org/10.4322/cto.2013.037

27. Rocha IA, Sá ANP, Braga LAV, Ferreira MO Filha, Dias MD. Community Integrative Therapy: situations of emotional suffering and patients' coping strategies. Rev Gaúcha Enferm. 2013;34(2):155-62. doi:http://dx.doi. org/10.1590/S1983-14472013000300020.

28.Silva FR, Assis SG. Prevenção da violência escolar: uma revisão da literatura. Educ Pesqui. 2018; 24. e157305. doi: http://dx.doi.org/10.1590/ s1517-9702201703157305.

29.Leme VBR, Del Prette ZAP, Coimbra S. Social skills, social support and well-being in adolescents of different family configurations. Paidéia. 2015;25(60):9-18. doi: http://dx.doi.org/10.1590/1982-43272560201503. 


\section{Contribuição dos autores}

Concepção e planejamento do estudo: Adriana Olimpia Barbosa Felipe e Denis da Silva Moreira. Obtenção dos dados: Adriana Olimpia Barbosa Felipe, Denis da Silva Moreira, Vânia Regina Bressan e Sueli de Carvalho Vilela. Análise e interpretação dos dados: Adriana Olimpia Barbosa Felipe, Denis da Silva Moreira, Zelia Marilda Rodrigues Resck, Silvana Maria Coelho Leite Fava. Vânia Regina Bressan e Silvana Maria Coelho Leite Fava Redação do manuscrito: Adriana Olimpia Barbosa Felipe, Denis da Silva Moreira, Zelia Marilda Rodrigues Resck, Vânia Regina Bressan, Sueli de Carvalho Vilela, Silvana Maria Coelho Leite Fava. Revisão crítica do manuscrito: Adriana Olimpia Barbosa Felipe, Zelia Marilda Rodrigues Resck, Denis da Silva Moreira e Silvana Maria Coelho Leite Fava

Todos os autores aprovaram a versão final do texto.

Conflito de interesse: os autores declararam que não há conflito de interesse.

Esta licença permite que outros remixem, adaptem e criem a partir do seu trabalho para fins não comerciais, e embora os novos trabalhos tenham de lhe atribuir o devido crédito e não possam ser usados para fins comerciais, os usuários não têm de licenciar esses trabalhos derivados sob os mesmos termos. 